\begin{tabular}{|c|l|}
\hline Title & Psychological interventional approach for reduce resource consumption : Reducing plastic bag usage at supermarkets \\
\hline Author(s) & Ohtomo, Shoji; OHNUMA, Susumu \\
\hline Citation & $\begin{array}{l}\text { Resources, Conservation and Recycling, 84, 57-65 } \\
\text { https://doi.org/10.1016/.resconrec.2013.12.014 }\end{array}$ \\
\hline Issue Date & 201403 \\
\hline Doc URL & http://hdl.handle.net/2115/56092 \\
\hline Type & article (author version) \\
\hline File Information & RECYCL.pdf \\
\hline
\end{tabular}

Instructions for use 


\section{Psychological interventional approach for reduce resource consumption: reducing plastic bag usage at supermarkets}

Shoji Ohtomo a and Susumu Ohnuma ${ }^{\mathrm{b}}$

a Department of Psychology, Faculty of Human Sciences, Konan Women's University, 6-2-23, Morikita-machi, Higashinada-ku, Kobe, 6580001, Japan

${ }^{\mathrm{b}}$ Department of Behavioral Science, Graduate School of Letters, Hokkaido University, North 10 West 7 , Kita-ku, Sapporo, 0600810, Japan

Corresponding author at: Department of Psychology, Faculty of Human Sciences, Konan Women's University, 6-2-23, Morikita-machi, Higashinada-ku, Kobe, 6580001, Japan. Tel: +81-78-413-3021. E-mail: s.ohtomo@konan-wu.ac.jp (S. Ohtomo). 
1 Psychological intervention to reduce resource consumption: reducing plastic bag usage at supermarkets

\section{Abstract}

6 A field study was conducted to investigate the reduction of plastic bag usage at 7 supermarkets. Many behaviors leading to potential damage to the environment may be 8 unintentional. This study applied a dual motivation model to plastic bag usage and 9 examined the effects of an intervention aimed at promoting pro-environmental 10 behavior. A voice prompt intervention was implemented in Japanese supermarkets. In 11 the first (control) week, shoppers were given free plastic bags by the cashier. In the 12 second (intervention) week, cashiers asked shoppers whether they wanted 13 plastic bags. We collected observational and questionnaire measures of 14 variables that predicted free plastic bag usage during the intervention. 15 The results supported a dual motivation model of behavioral change. The 16 voice prompt decreased the usage of plastic bags by both discouraging 17 unintentional usage and encouraging an intentional reduction in usage. 18 Possibilities for interventions designed both to attenuate unintentional 19 motivation and to promote intentional motivation are considered.

21 Keywords: behavioral change, behavioral intention, behavioral 22 willingness, plastic bag usage, voice prompt. 


\section{Introduction}

"Think Globally, Act Locally" is one of the most famous slogans in environmental activism. Because local activity is necessary to reduce carbon dioxide emissions, an interventional approach (e.g., Bamberg et al., 2003; Heath and Gifford, 2002) is one of the recommended strategies for encouraging individuals to engage in pro-environmental behaviors in their everyday life. Reduction of the usage of plastic bags is an effective 31 pro-environmental behavior that relatively few people engage in, despite the small effort required to do so (e.g., Ayalon et al., 2009; Convery et al., 2007; Funaki, 2006). In particular, most Japanese supermarkets provide

34 free plastic bags for shoppers to carry their purchases, and consumers use 35 these bags excessively. According to one estimate (Funaki, 2006), 302 36 thousand tons of plastic, (i.e., 44 billion plastic bags), that is $24 \mathrm{~kg}$ (i.e., 37360 plastic bags) per person, are consumed every year in Japan. Another 38 study (Eco-Design Forum for Civic Society, 2010) estimated that one person not using plastic bags for a single year would reduce carbon dioxide emissions by $18.9 \mathrm{~kg}$. Therefore, reducing the usage of plastic

41 bags is considered one of the most simple and effective resource reduction 42 behaviors that everyone can perform on a daily basis.

A few people strive to reduce their usage of free plastic bags. Although most people in Japan are environmentally concerned and have some reusable plastic bags, they often use free plastic bags at supermarkets. Funaki (2006) revealed that approximately $30 \%$ of plastic

47 bags in households, obtained for free while shopping, are disposed 48 without being used at all, and there are five plastic bags in disposed 49 wastes on average. According to the estimate of the Global Warming White 
50 Paper (2013), over 300 plastic bags per person are consumed every year.

51 Usage of free plastic bags at supermarkets is a repetitive type of behavior 52 in daily life, which is acknowledged as a habit (Aarts and Dijksterhuis, 53 2000; Ouellette and Wood, 1998). The habituation of free plastic bag use 54 induced an inconsistency between people's environmental concern and 55 their actual behavior. Through repetition of behavior in the same context 56 (e.g., regular supermarket), plastic bag usage is likely to become a 57 habitual behavior that is activated automatically. People who have formed 58 a habit behave automatically by reacting habitually in the same behavioral 59 setting, without further consideration of other available alternatives 60 (Danneret al., 2008; Neal et al., 2011). Thus, habitual behavior is elicited 61 automatically by a response to the behavioral context regardless of 62 environmental concerns, as long as the behavioral context is stable.

63 Although there have been some field experiments aimed at 64 promoting environment-friendly behavior, particularly in relation to 65 travel mode choice and water and energy conservation (Bamberg et al., 66 2003; Heath and Gifford, 2002; Verplanken et al, 1998), only a few field 67 studies have focused on and measured habits for promoting resource 68 reduction behaviors. Knussen and Yule (2008) investigated the role of 69 recycling habits in the disposal of household waste. They suggested that 70 the lack of a recycling habit was an obstacle to behavioral change. 71 Therefore, the purpose of this study was to conduct a field study to 72 intervene in the behavioral context that induced habitual behavior and to 73 clarify psychosocial determinants of environmentally friendly behavior. 


\section{Theoretical framework}

78

79

80

81

82

83

84

86

The theory of planned behavior (TPB: Ajzen, 1991; Ajzen and Madden, 1986) has been one of most frequently cited models, in many domains of social science, for understanding some psychosocial determinants of human social behavior (Nosek et al., 2010). The TPB postulates that human actions are a result of consciously controlled or deliberative decision-making. According to the TPB, an attitude does not directly determine behavior, but does so only indirectly via a behavioral intention, which is a deliberative motivation. The TPB also stresses the importance of social influences in the behavioral decision. In addition to the influence of attitude, the behavioral intention is also determined by perceived behavior control (PBC), which reflects the extent to which an individual feels it to be easy or difficult to perform the behavior in a given situation.

A subjective norm is viewed as a third factor influencing behavioral intention. In the framework of TPB, a subjective norm is conceptualized as a social pressure derived from the expectations of important reference persons or groups regarding whether a behavior should or should not be performed.

The TPB has been successfully applied to examine the psychosocial determinants of resource reduction behaviors. For example, a study by Thøgersen (1994) suggested the utility of the TPB framework to reveal the motivational process of recycling behavior. Tonglet et al. (2004a) applied TPB to identify the determinants of recycling behavior in a local curbside recycling scheme, and suggested that attitude and past recycling behavior were the important determinants of intention. Moreover, Tonglet et al. (2004b) showed that different factors are involved in waste minimization and recycling behaviors. Knussen et al. (2004) also examined recycling behavior using the TPB framework. They reported that the relationship between perceived behavioral control and behavioral intention was weaker for people who 
104 perceived that they lacked facilities for recycling.

105 However, recent studies have suggested the framework of TPB has a limited 106 ability to predict behavior, because the TPB model is premised on deliberative or 107 intentional decisions (Gerrard et al., 2008). In a meta-analysis of studies applying the 108 TPB to environmental behavior, Bamberg and Möser (2007) reported that behavioral 109 intention (i.e., the proximal antecedent of behavior) explained only $27 \%$, on average, 110 of the variance in environmental behavior. In addition, the results of a meta-analysis 111 of intervention studies based on the TPB framework indicated that changes in 112 intention engendered fewer changes in behavior (Webb and Sheeran, 2006). These 113 findings suggest that the inconsistency between behavioral intention and actual 114 behavior might be caused by a "habitual reaction" or a "non-intentional route to 115 behavior," regardless of behavioral intention.

116 In an effort to improve the predictive power of TPB, the prototype model 117 examines behavior in terms of not only intentional motivation but also unintentional 118 motivation (Gibbons et al., 1998; Gibbons et al., 2009). The prototype model assumes 119 that two types of motivation are involved in social behavior. The first is behavioral 120 intention (Ajzen, 1991; I intend to do an action), which is conscious deliberation 121 leading to intended behavior (similar to TPB). The second is behavioral willingness 122 (Gibbons et al., 1998; a given situation elicits an action), which is a reaction to a 123 situation leading to unintended or unplanned behavior. Behavioral willingness is 124 considered as the unintentional motivation that is elicited by circumstances conducive 125 to impulsive or spontaneous behavior, regardless of the individual's intention 126 (Gerrard et al., 2008; Gibbons et al., 2006). The dual-process perspective of this 127 model is able to predict both intended behaviors based on a conscious motivation, and 128 unintended behaviors based on a spontaneous reaction to a given context (Gibbons et 129 al., 2009). The prototype model has been found to be effective where the behaviors are 130 determined not only by intention, but also by unintended behavioral willingness, 
131 particularly in predicting socially undesirable behaviors such as risky sexual activity

132 (Gibbons et al., 1998; Thornton et al., 2002) and use of substances such as alcohol, 133 tobacco, and drugs (Gerrard et al., 2002; Gibbons et al., 2004).

134 Ohtomo and Hirose (2007) extended the prototype model to apply to recycling 135 behavior. This model focused on the effects of contrary motivations (i.e., behavioral 136 intention vs. behavioral willingness), to reveal the intention-behavior gap in 137 environmental behavior. Their results showed that recycling behavior was determined 138 by both behavioral intention (i.e., conscious motivation) toward eco-friendly behavior, 139 and behavioral willingness (i.e., unintentional motivation) based on a reaction to a 140 situation affording eco-unfriendly behavior (Fig. 1). This indicated that recycling 141 behavior was promoted or inhibited, depending upon whether the intentional 142 motivation or the unintentional motivation was more salient. They also tested the 143 antecedent factors of these dual motivations and found that behavioral intention was 144 affected by both a subjective norm (i.e., perceived approval or disapproval by others) 145 and attitude toward the environment, while behavioral willingness was affected by a 146 descriptive norm (i.e., perceptions of how most people behaved). Therefore, the 147 framework of the prototype model is appropriate for examining the different processes 148 affecting pro-environmental behavior, including both intentional motivations based 149 on individuals' volition, and unintentional motivation elicited by given situations. 150 This model is also suitable for exploring the determinants of such dual motivations.

151 However, little research has examined the dual-motivation model in a real situation, 152 particularly in relation to interventions aimed at changing non-intentional routes (i.e., 153 willingness-behavior relationships) to habitual eco-unfriendly behaviors.

\section{3. The present study}

157 This study implemented an intervention to reduce the usage of plastic bags at 
158 supermarkets, in order to examine the effects of an intervention based on the 159 dual-motivation model (Fig. 1). In most Japanese supermarkets, when shoppers 160 purchase products, the cashiers give them free plastic bags and say nothing about the 161 usage of plastic bags. However, if shoppers do not want to use the free plastic bags, 162 they have to actively decline them. Such circumstances inhibit pro-environmental 163 behavior (i.e., avoiding plastic bag use), and induce people to receive free plastic bags, 164 thus unintentionally promoting their use.

165 The present study introduced a simple "voice prompt intervention" to activate 166 an eco-friendly intention, in order to encourage a reduction in the use of free plastic 167 bags. In the intervention, cashiers asked to shoppers, inquiring whether they wanted 168 plastic bags or not, and gave bags to shoppers only if the response was affirmative. A 169 prompt is a visual or auditory cue that reminds people to carry out a target behavior. 170 According to McKenzie-Mohr and Smith (1999), the effect of a prompt is not to 171 persuade people to change their behavior, but to recall people's consciousness toward 172 an action that they intended to perform. In previous studies, a prompt has been shown 173 to be an effective intervention, such as in the purchase of returnable bottles (Geller et 174 al., 1971), promotion of recycling actions (Austineet al., 1993), and control of 175 littering (Houghton, 1993). DiClemente and Hantula (2003) reviewed that prompt is 176 one of the effective interventions for pro-social consumer issues (e.g., 177 pro-environmental and health care behaviors). However, these studies focused on the 178 direct effect of the prompt on the behavior, but did not examine the effect on the 179 motivational processes that determine the behavior.

180 Accordingly, the present study tested the effect of voice prompt as a reminder 181 that activates individual intention. We formulated the following hypotheses:

182

183 Hypothesis 1-1. The introduction of prompt intervention would cause a shift from 184 unintended (habituated) behavior to intended behavior in shoppers. 
185 Hypothesis 1-2. The voice prompt intervention induces a context change, which 186 should mitigate the influence of the situation affording habitual free plastic use, and 187 then decrease bag usage.

188

189 This context change was expected to improve the psychosocial determinants of 190 shoppers' behavior. That is, the voice prompt intervention would activate a 191 consciousness toward discouraging plastic bag usage, causing the intended behavior 192 of rejecting the offer to use the plastic bags. Thus, the following was hypothesized:

193

194 Hypothesis 2. The behavioral intention, which is the conscious motivation to reduce 195 the use of plastic bags, would have a greater effect on the target behavior in the 196 presence of the intervention than in its absence.

197

198

199 persuasive message (i.e., "You should reduce the usage of free plastic bags for 200 environmental conservation"), but a neutral message serving as a reminder of 201 behavioral choice (i.e., "Do you want free plastic bags?"). Because the voice prompt 202 does not produce a persuasive effect, the attitude to plastic bag usage would not be 203 changed. However, if the intervention changes the perception of other people's plastic 204 bag use, then social norm factors, such as a descriptive norm and an injunctive norm 205 might be reconsidered. Previous studies demonstrated that an intervention changed 206 the perceptions of a descriptive norm (Heath and Gifford, 2002) and a subjective norm 207 (Bamberg et al., 2003). Thus, we hypothesized the following:

208

209 Hypothesis 3-1. Shoppers may perceive that most shoppers receive free plastic bags in 210 the post-intervention than in the pre-intervention.

211 Hypothesis 3-2. Shoppers would also perceive a stronger expectation of not receiving 
212 free plastic bags in the post-intervention assessment than in the pre-intervention 213 assessment.

214

215 A voice prompt intervention was also expected to improve the PBC over 216 reduction of free plastic bag usage. A study of interventions (Heath and Gifford, 2002)

217 indicated that once people began to change their behavior as a result of an intervention, 218 they developed less biased and more realistic perceived behavioral control. Thus, we 219 hypothesized the following:

220

221 Hypothesis 4. People would evaluate PBC as more positive after reducing their usage 222 of plastic bags, as a result of the voice prompt intervention. In addition, influence of 223 PBC on behavior would become stronger during post-intervention than during 224 pre-intervention.

225 antecedents on pro-environmental motivation differ depending on the behavioral 229

230 Hypothesis 5. Improvements in the antecedents of dual motivations strengthen the 231 effect of behavioral intention on the behavior and weaken the effect of behavioral 232 willingness.

233

To test these hypotheses in the field, we collected two types of data: observations 235 of shoppers' actual plastic bag use at supermarkets, and responses to a questionnaire 236 that measured components of the dual-motivation model. 


\subsubsection{Intervention procedure}

242 In 2007, the voice prompt intervention was implemented at four medium-sized 243 supermarkets in Hokkaido, Japan. All the four supermarkets were located in urban 244 areas that were at a 30-min (approx.) driving distance from the city center; however, 245 they were not large shopping malls. Some customers would stand chatting together 246 inside the shops. The study consisted of two phases, pre- and post-intervention.

247 During the first week, which was the pre-intervention phase, shoppers were given free 248 plastic bags by the cashier, who said nothing about the usage of plastic bags (as is 249 typical). In the second week, the post-intervention phase, cashiers asked shoppers 250 whether they wanted plastic bags. During the intervention, the cashiers did not offer 251 any plastic bags until the shoppers answered "yes," "please," or a similar response. 252 Some might wonder what the alternative choice was for those who had not brought 253 their own bags. Typical observed behaviors were a) shoppers using cardboard boxes, 254 which they could get for free from the shops; b) shoppers taking out folded bags from 255 their handbags, particularly middle-aged and elderly women; and c) several shoppers 256 purchasing reusable shopping bags sold at cash counters. The intervention was 257 continued during the second week even when data collection (observation and 258 questionnaires, as described below) was not conducted.

\section{4.1.2 Observation of behavior}

260 As shoppers paid their bill at the checkout counter, the investigators 261 unobtrusively observed the checkout counter from a distance and recorded whether 262 each shopper received or declined free plastic bags.

263 The first (pre-intervention) collection of behavioral data was implemented at 264 each supermarket on Wednesday or Saturday of the same week. For two of the 
265 supermarkets, data collection was implemented on the Wednesday from 10.00 to 12.00 , 266 from 13.00 to 15.00 , and from 16.00 to 18.00 . For the other two supermarkets, the data 267 collection was implemented on the Saturday. In the second (post-intervention) phase 268 of data collection, the procedures were identical to those used in the pre-intervention 269 phase. The total number of shoppers who were observed at the checkout counter was 2704105 in the pre-intervention phase, and 4057 in the post-intervention phase.

271 Questionnaire: Immediately after each shopper paid the bill and went through 272 the checkout counter, investigators (who were different from the observers) gave the 273 shopper a questionnaire, with instructions to answer it at home and send it back by 274 mail. The place and time of data collection were the same as for the observational data 275 collection. The only difference was that in the second week (post-intervention), the 276 investigators ensured that the shoppers were not the same participants who had 277 already participated in the pre-intervention phase. If participants had already 278 answered the questionnaire in the pre-intervention phase, they were not asked to 279 complete or return it. We had to obtain data from different individuals as the analysis 280 design was between samples, and it could not be within samples due to the strict 281 requirement of anonymity.

Each of the constructs included in the questionnaire was assessed using two or 284 three questionnaire items. With one exception (anti-plastic bag behavior: see below) 285 respondents were asked to rate items on 5-point scales ranging from 1 (completely 286 disagree) to 5 (completely agree).

287 Attitude: Two items were used to access attitude: "I think I should take action to 288 reduce the usage of plastic bags" and "I think using plastic bags is harmful to the 289 environment." The two items were averaged to give an attitude mean score $(\alpha=.76)^{1}$. 290 Subjective norm: Two items were used to access subjective norm: "Most 
291 people who are important to me (e.g., family or friends) would support a decision not

292 to receive free plastic bags" and "Most people would approve of me not receiving free

293 plastic bags." The two items were averaged to give a subjective norm mean score ( $\alpha$ $294=.69)$.

Descriptive norm: Two items were used to access descriptive norm: "Most 296 people receive free plastic bags" and "Most people do not bring shopping bags as an 297 alternative to receiving new free plastic bags." The two items were averaged to give a 298 descriptive norm mean score $(\alpha=.68)$.

299 Perceived behavioral control: Three items were used to access perceived 300 behavioral control: "It is easy for me to decline free plastic bags," "It is inconvenient 301 for me to bring reusable shopping bags (reversed item)," and "If I want to, I can use 302 reusable shopping bags instead of free plastic bags." After the scores of the reversed 303 item was reversed, the three items were averaged to give a perceived behavioral 304 control mean score $(\alpha=.76)$.

305 Behavioral intention: Two items were used to access behavioral intention: "I 306 intend not to receive free plastic bags" and "I intend to go shopping with reusable 307 shopping bags in the future." The two items were averaged to give a behavioral 308 intention mean score $(\alpha=.85)$.

309 Behavioral willingness: The procedure of Ohtomo and Hirose (2007) was 310 adapted to evaluate free plastic bag usage. To access behavioral willingness, 311 participants were asked to imagine themselves in the two different hypothetical 312 situations that afford environmental unfriendly behavior and then indicate what they 313 willing to do under those situations. The first situation was: "If a cashier gives me free 314 plastic bags spontaneously, I am likely to receive them without thinking too much." 315 The second situation was "In a daily situation, I am likely to receive the free plastic 316 bags unconsciously." The two items were averaged to give a behavioral willingness 317 mean score $(\alpha=.85)$. 
Anti-plastic bag behavior: Two items were used to access anti-plastic bag

319 behavior: The first item was measured by responses to the following question: "How 320 often do you decline free plastic bags during daily shopping?" Respondents were 321 asked to rate on a 4-point scale ranging from 1 (never decline) to 4 (always decline).

322 The second item was measured by responses to the following question: "When you 323 purchase some goods, how often do you use your own bag instead of receiving free 324 plastic bags?" Respondents were asked to rate on a 5 -point scale ranging from 1 (never 325 do) to 5 (always do). For analysis, the two items were standardized because these two 326 behaviors were measured with different point scales. Afterwards, the two standardized 327 items were averaged to give an anti-plastic bag behavior mean score $(\alpha=.62)$.

\section{5. Results}

As shown in Table 1 , about $78 \%$ of shoppers received free plastic bags, and $33222 \%$ of shoppers declined the bags during the pre-intervention phase. In addition, 333 about $73 \%$ of shoppers received free plastic bags, and $27 \%$ of shoppers declined the 334 bags in the post-intervention phase. There was a significant difference in the 335 proportions between pre- and post-intervention phases $\left(\chi^{2}(1)=37.55, p<.001\right)$. Thus, 336 the intervention including the voice prompt made shoppers less inclined to use free 337 plastic bags. Furthermore, there was no significant difference in the proportions 338 between Wednesday and Saturday $\left(\chi^{2}(1)=.03, p=.857\right)$.

\subsection{Demographics}

Figure 2 shows the results of the collection of questionnaires. We analyzed 341 accurate questionnaire data (pre-intervention $n=448$, post-intervention $n=435$ ). The 342 demographics in the pre- and post-intervention phases are shown in Table 2. There are 
343 no statistical differences in gender, age, or occupation between pre and post samples.

344 Therefore, from the results, it appears that the samples in the pre- and 345 post-intervention periods were essentially equivalent.

346

347 5.3. Comparison of psychological constructs between pre-and post-intervention 348 samples

Table 3 shows the means and standard deviations of the constructs of the 350 dual-motivation model in the pre- and post-intervention samples. We implemented a 351 linear mixed model analysis because the four different supermarkets were nested 352 within intervention. The results indicated that attitude was almost unchanged between 353 the pre- and post-intervention samples (intervention; $F(1,862)=1.79$; intervention 354 (supermarket $)=F(6,862)=.97)$. However, subjective norm, descriptive norm, 355 perceived behavior control, behavioral intention, behavioral willingness, and anti-plastic behavior changed from the pre- to the post-intervention assessment ( $F \mathrm{~s}>$ $3578.46, p<.01)$. Also, these effects on subjective norm, descriptive norm, behavioral 358 intention, behavioral willingness, and anti-plastic behavior differed between the 359 supermarkets $(F \mathrm{~s}>2.25, p<.05)$. Therefore, although some constructs were not 360 equally affected between the supermarkets, overall, the intervention affected the 361 constructs of the dual-motivation model, except for attitude.

362

363 5.4. Differences in the dual model between the pre- and post-intervention samples Table 4 lists the correlations between the constructs in the pre- and 365 post-intervention samples. To examine the differences in the dual-motivation model 366 (Fig. 1) between the pre- and post-intervention samples, a multi-group analysis was 367 conducted $^{2}$. First, an unconstrained model was estimated which does not assume equal 
368 path coefficients in the two samples for the constructs of the dual-process model $\left(\chi^{2}\right.$ $369(12)=82.49, p<.01$, GFI $=.97$, CFI $=.98$, RMSEA $=.08)^{3}$. Second, a fully 370 constrained model was estimated which assumes equal path coefficients for the two 371 samples $\left(\chi^{2}(21)=121.38, p<.01, \mathrm{GFI}=.96, \mathrm{CFI}=.95, \mathrm{RMSEA}=.07\right)$. Thus, giving 372 up the constraints of equal path coefficients results in a significantly better model fit $373\left(\chi^{2}(9)=38.89, p<.01\right)$. As a last step, several constrained models were tested. All

374 paths between the constructs that seemed to show a statistically significant difference 375 in their coefficients in a fully-constrained model were additionally freed of equal path 376 constraints. A chi-square difference test was conducted to see if the additional path 377 release led to a statistically weaker model fit.

378 Table 5 shows the fit indexes of the constrained models and the unconstrained 379 model. The results show that a model without the constraints of equal path coefficients 380 from behavioral willingness and behavioral intention to behavior, from descriptive 381 norm to behavioral willingness and behavioral intention, and from perceived 382 behavioral control to behavioral intention and behavior, fit the data better $\left(\chi^{2}(17)=\right.$ $38388.86, p<.01, \mathrm{GFI}=.97, \mathrm{CFI}=.97, \mathrm{RMSEA}=.07)$. In particular, the Akaike 384 Information Criterion (AIC) ${ }^{4}$, which is used to compare competing models, indicates 385 a better fit of the unconstrained model $($ AIC $=166.86)$ relative to the other models 386 (AIC > 169.95).

387 Figure 3 shows the unstandardized and standardized path coefficients for the 388 pre- and post-intervention samples. The results indicate that the effect of behavioral 389 willingness on anti-plastic bag behavior was weaker in the post-intervention sample ( $\beta$ $390=-.12, p<.01)$ than in the pre-intervention sample $(\beta=-.22, p<.01)$. On the other 391 hand, the effect of behavioral intention on anti-plastic bag behavior was stronger in 392 the post-intervention sample $(\beta=.37, p<.01)$ than in the pre-intervention sample $(\beta$ $393=.25, p<.01)$. Furthermore, the effect of perceived behavioral control on behavioral 394 intention was stronger in the post-intervention sample $(\gamma=.65, p<.01)$ than in the 
395 pre-intervention sample $(\gamma=.50, p<.01)$. Although the influence of perceived

396 behavioral control on behavior was non-significant in the pre-intervention sample $(\gamma$ $397=.04, p=.39)$, this effect was significant in the post-intervention sample $(\gamma=.19, p$ $398<.01)$.

\section{Discussion}

401

This study controlled the effects of the behavioral context using a voice 403 prompt intervention that draws people away from habitual usage to reduce the usage of 404 free plastic bags. Observations of shoppers' behavior showed that implementation of 405 the voice prompt intervention caused a 5\% reduction in free plastic bag usage, which 406 demonstrates the effectiveness of the intervention. Although a 5\% reduction does not 407 appear to be a large effect, it is substantial, considering that shoppers did not 408 necessarily have a reusable shopping bag with them at the time of the intervention, and 409 thus many could not have refused the free plastic bag. One possible interpretation is 410 that some repeat shoppers changed their behavior during subsequent opportunities 411 after an initial exposure to the intervention. Another interpretation is that those who 412 happened to bring their own bag or who bought only a few small purchases did not 413 asked for plastic bags. However, the questionnaire data showed that intervention 414 improved the tendency to decline free plastic bags. Therefore, the results from both 415 observational and questionnaire data indicate significant effects of the voice prompt 416 intervention. These results are consistent with hypothesis 1-2.

417 The context change brought about by the intervention changed the motivational 418 process of free plastic bag usage. The intervention led people to decrease the 419 unintentional motivation to use plastic bags (i.e., behavioral willingness), and 420 increase the intentional motivation not to use plastic bags (i.e., behavioral intention). 421 These results indicate that there is a stronger connection between behavior and 
422 intention to reduce the use of plastic bags as a result of the voice prompt intervention.

423 Moreover, the effects of motivational factors (intention and/or willingness) on

424 anti-plastic bag behavior were different between the pre- and post-intervention phases.

425 The intervention attenuated the influence of behavioral willingness to engage in

426 habitual, automatic usage of plastic bags (paths (a) and (a') in Figure 3). On the other

427 hand, the intervention strengthened the influence of the behavioral intention to reduce

428 usage of plastic bags voluntarily (paths (b) and (b') in Figure 3). These results indicate

429 that Hypotheses 1-1 and 2 are supported. Thus, our findings suggest that the voice

430 prompt intervention served to make people more attentive and deliberative in their

431 usage of plastic bags. Hence, people's behavior was more likely to be guided by an

432 intentional motivation based on the conscious intention to reduce the usage of plastic

433 bags, rather than an unintentional motivation to go along with a situation in which

434 plastic bags are automatically provided and received.

435 Concerning normative factors, as hypothesis 3-1 predicted, the difference in

436 the descriptive norm between pre-and post-intervention samples indicated that people

437 came to believe that fewer people would take plastic bags. As hypothesis 3-2 predicted,

438 the difference between pre- and post-intervention samples for the subjective norm

439 indicated that people came to perceive a stronger social pressure to reduce the usage

440 of plastic bags. This change might not be a direct effect of voice prompt; it may be

441 because shoppers noticed changes in others' behaviors. In other words, people might

442 become more sensitive to these norms because they looked around at other people

443 when they were being spoken to and found that others were actually not using plastic

444 bags. Although we could not differentiate between these reasons, intervention

445 changed the social influence related to plastic bag usage.

446 The effects of perceived behavioral control were found to vary depending on

447 the intervention. Compared to the pre-intervention sample, perceived behavioral

448 control enhanced behavioral intention and anti-plastic bag behavior strongly in the 
449 post-intervention sample (paths (c) and (c') in Figure 3). This result suggests that, as

450 a result of the intervention, people were able to choose their behavior deliberately or

451 thoughtfully, and thus self-control over the use or non-use of plastic bags was

452 strengthened. Hence, people were more likely to engage in the intended behavior

453 under the regulation of perceived behavioral control. A previous study also reported

454 that perceived behavioral control shaped behavioral intention strongly when the

455 intervention disrupted automatic execution of the behavior and initiated deliberate

456 action (Bamberg et al., 2003). Klöckner and Matthies (2009) also examined the

457 influence of perceived behavioral control and suggested that the influence of

458 perceived behavioral control is adjustable depending on the setting, i.e., the structural, 459 psychical, and social changes. Thus, the context change induced by our intervention 460 attenuated a habitual response and promoted intentional control over plastic bag usage. 461 According to Ajzen (1991), the direct relationship between perceived behavioral 462 control and behavior reflects actual control with some degree of accuracy. Our finding 463 indicates that the voice prompt improved the accuracy of behavioral control and 464 produced a direct effect on the behavior. Therefore, we confirmed that perceived 465 behavior control was improved by the intervention in accordance with hypothesis 4 .

\section{7. Conclusions}

We designed a field study in supermarkets and used shoppers as the sample. A 470 voice prompt intervention succeeded in activating anti-plastic bag use behavior by 471 drawing shoppers into the influence of motivational processes. As a result of the 472 week-long intervention, shoppers were able to take an intended pro-environmental 473 action purposively, rather than spontaneously receiving plastic bags based on a 474 habitual reaction to the situation. The behavioral change brought about by the 475 intervention resulted from an increase in cognitive activation that caused a switch 
476 from the execution of unintended behavior to that of intended behavior. These results

477 are consistent with the hypothesis 5. However, this study only measured the effects of 478 the week-long intervention shortly after its implementation and did not examine how 479 long the intervention effect persisted. Although the supermarkets reported a higher 480 plastic bag refusal rate among shoppers (about $20 \%$ before intervention and about $25 \%$ 481 one week after intervention), after six months, it had increased to nearly $40 \%$ as a 482 result of continuous interventions including the voice prompt (RALS, 2008). This 483 suggests that continuous intervention would be more effective; however, this study 484 could not capture any longer-term effects. Further studies should be conducted to 485 investigate the long-term effects of voice prompt. Furthermore, this study recorded 486 only the number of received and declined plastic bags but not the number of plastic 487 bags distributed for free. It was impossible for observers to keep track of the number 488 of plastic bags because they were standing at a distance from the cashiers so as not to 489 disturb their work. It might have been more effective if the number of plastic bags 490 distributed could have been counted. However, most consumers usually take only one 491 plastic bag, and the cashiers give plastic bags according to the amount of goods 492 purchased. Thus, there is no substantial difference between the decline rate and the 493 number of distributed plastic bags.

494 The present study has profound implications for pro-environmental

495 interventions. A voice prompt can be introduced at a low cost, compared to other 496 popular economic incentives (e.g., an extra charge for plastic bags). Implementation 497 of a prompt requires only a simple manipulation for a targeted behavioral context (i.e., 498 asking). Although this study did not examine the effects of economical incentive, it 499 would be worthy to combine the interventional approach used in this study to examine 500 it. Indeed, results from another study showed that charging for plastic bags alone 501 failed to reduce their usage in Taiwan (Asari et al., 2008). Businesses usually hesitate 502 to charge extra for plastic bags because they are afraid of losing their customers to 
503 competitive shops and damage their profits. The Environmental Agency- Japan used to 504 discuss the implementation of extra charge for plastic bags; however, unions and 505 supermarket companies opposed it, while consumer groups approved of it (Ministry of 506 the Environment, 2006). Every stakeholder understood that it was delicate to adopt a 507 stringent regulation to charge extra for plastic bags, which implied that it was difficult 508 to control those not obeying the rule. This is because unions and companies opposed 509 the new rule of charging extra for plastic bags. They are afraid of freeriders that do not 510 implement the extra charge for plastic bags to retain customers. Accordingly,

511 voluntary cooperation, such as voluntary agreement, is recommended to reduce the

512 fear of losing customers, with the commitment of consumer groups ${ }^{6}$. Implementation

513 of economic incentive sometimes provokes controversy, which underlies the potential

514 barrier against achieving successful reduction of plastic bag usage. On the contrary,

515 the voice prompt intervention is a useful measure for avoiding controversy. As our

516 study has suggested, the voice prompt intervention induced a behavioral change.

517 However, implementation of a prompt requires specification of the context that relates

518 to the targeted pro-environmental behavior. Further field research on various

519 pro-environmental behaviors is required to fully optimize the applicability of the 520 prompt intervention as well as the dual motivation model. Our model of

521 pro-environmental behavior remains to be improved through additional research. 
$524{ }^{1}$ The " $\alpha$ " indicates the Cronbach alpha reliability index.

$525{ }^{2}$ Amos 20.0 was used for the analysis.

$526{ }^{3}$ Chi-square test is used for testing hypothesis to evaluate the appropriateness of the 527 structural equation model. However, as is often the case for large samples, there is a 528 significant discrepancy between predicted and obtained covariance structures. The fit 529 between structural model and data were evaluated by means of standard indexes: 530 goodness-of-fit (GFI), comparative fit index (CFI), and root mean square error of 531 approximation (RMSEA). GFI and CFI estimates can vary from 0 to 1 , and a good fit 532 is indicated by values above .90 or .95 . RMSEA is bounded below by zero, and a good 533 fit is indicated by values below .05 or .08 .

$534{ }^{4}$ The AIC is used to select between competing models. A lower AIC value indicates a 535 better fitting model (Schermelleh-Engel et al., 2003).

$536{ }^{5}$ Until the end of 2011, many supermarkets charged extra for plastic bags following 537 the voluntary agreement with municipalities and consumer groups (Ministry of 538 Environment, 2012). 
541 The authors are grateful for the cooperation of RALSE Co., Ltd., and Dolphin Mothers 542 Co., Ltd. for conducting the large-scale intervention in the supermarkets. 543 


\section{References}

Aarts H, Dijksterhuis Ap. Habits as knowledge structures: Automaticity in goal-directed behavior. J Personal Social Psychol 2000;78:53-63.

Ajzen I. The theory of planned behavior. Organ behave Hum Decision Processes 1991;50:179-211.

Ajzen I, Madden TJ. Prediction of Goal-Directed behavior: Attitudes, intentions, and perceived behavioral control. J Exp Social Psychol 1986;22:453-74.

Asari M, Sato N, Sakai S, Nakamura K, Gunjima T. Plastic shopping bag waste from the quantity-quality viewpoints: present status and vision. Jpn J Waste Manag 2008;19:187-93.

Ayalon O, Goldrath T, Rosenthal G, Grossman M. Reduction of plastic carrier bag use: An analysis of alternatives in Israel. Waste Management 2009:29: 2025-2032.

Bamberg S, Ajzen I, Schmidt P. Choice of travel mode in the theory of planned behavior: The roles of past behavior, habit, and reasoned action. Basic Appl Social Psychol 2003;25:175-87.

Bamberg S, Hunecke M, Blöbaum A. Social context, personal norms and the use of public transportation: Two field studies. J Environ Psychol 2007;27:190-203.

Bamberg S, Möser G. Twenty years after Hines, Hungerford, and Tomera: A new meta-analysis of psycho-social determinants of pro-environmental behaviour. J Environ Psychol 2007;27:14-25.

Danner UN, Aarts H, de Vries NK. Habit vs. intention in the prediction of future behavior: The role of frequency, context stability and mental accessibility of past behavior. The Br J Social Psychol 2008;47:245-65.

Eco-Design Forum for Civic Society. (n.d.). Eco-Money. Retrieved January, 4, 2010, from http://eem.jp/jp/about02.html

Funaki K. The environmental economic policy of the "plastic shopping bag." Recycle 
Bunkasha; 2006.

Geller ES, Wylie RC, Farris JC. An attempt at applying prompting and reinforcement toward pollution control. Proceedings of the $79^{\text {th }}$ Annual Convention of the American Psychological Association 1971;6:701-2.

Gerrard M, Gibbons FX, Vande Lune LSV, Pexa NA, Gano ML. Adolescents' substance-related risk perceptions: Antecedents, mediators and consequences. Risk Decis Policy 2002;7:175-91.

Gerrard M, Gibbons FX, Houlihan AE, Stock ML, Pomery EA. A dual-process approach to health risk decision making: The prototype willingness model. Dev Rev 2008;28:29-61.

Gibbons FX, Gerrard M, Blanton H, Russel DW. Reasoned action and social relation: Willingness and intention as independent predictors of health risk. J Personal Social Psychol 1998;74:1164-80.

Gibbons FX, Gerrard M, Reimer RA, Pomery EA. Unintentional behavior: A subrational approach to health risk. In: de Ridder D, de Wit J, editors. Self-regulation in health behavior. UK: Wiley and Sons, Inc; 2006. p. 45-70.

Gibbons FX, Gerrard M, Vande Lune LS, Wills TA, Brody G, Conger RD. Context and cognitions: Environmental risk, social influence, and adolescent substance use. Personal Social Psychol Bull 2004;30:1048-61.

Gibbons FX, Houlihan AE, Gerrard M. Reason and reaction: The utility of a dual-focus, dual-processing perspective on promotion and prevention of adolescent health risk behavior. Br J Health Psychol 2009;14:231-48.

Global Warming White Paper. (n.d.). Plastic bags. Retrieved April, 10, 2013, from http://www.glwwp.com/main/bag.html.

Heath Y, Gifford R. Extending the theory of planned behavior: Predicting the use of public transportation. J Appl Social Psychol 2002;32:2154-89.

Houghton, S. Using verbal and visual prompts to control littering in high schools. 
Educ Studies 1993;19:247-54.

Klöckner CA, Matthies E. Structural Modeling of car use on the way to the university in different settings: Interplay of norms, habits, situational restraints, and perceived behavioral control. J App Social Psychol 2009;39:1807-34.

Knussen C, Yule F. "I' $m$ not in the habit of recycling" the role of habitual behavior in the disposal household waste. Environ Behav 2008;40:693-702.

Knussen C, Mackenzie J, Wells M, Yule F. An analysis of intention to recycle household waste: The role of past behaviour, perceived habit and perceived lack of facilities. J Environ Psychol 2004;24:237-46.

Lepper MR, Greene D. The hidden costs of reward. Hillsdale;Lawrence Erlbaum;1978.

Mckenzie-Mohr D, Smith W. Fostering Sustainable Behavior: An Introduction to Community-Based Social Marketing. Canada: New Society Publishers;1999.

Ministry of the Environment: Minutes of 42th sectional meeting of waste and recycling. 2006.

Ministry of Environment; Report of survey of plastic bags. 2012: http://www.env.go.jp/recycle/yoki/c_1_questionnaire/index.html

Neal DT, Wood W, Wu M, Kurlander D. The pull of the past: When do habits persist despite conflict with motives? Personal Social Psychol Bull 2011;37:1428-37.

Nosek B A, Graham J, Lindner NM, Kesebir S, Hawkins CB, Hahn C, Schmidt K, et al. Cumulative and career-stage citation impact of social-personality psychology programs and their members. Personal Social Psychol Bull 2010;36:1283-1300.

Ohtomo S, Hirose Y. The dual-process of reactive and intentional decision-making involved in eco-friendly behavior. J Environ Psychol 2007;27:117-25.

Ouellette JA, Wood W. Habit and intention in everyday life: The multiple processes by which past behavior predicts future behavior. Psychol Bull 1998;124:54-74.

RALS Co. Ltd. Annual report of RALS company for CSR; 2008. 
Schermelleh-Engel K, Moosbrugger H, Müller H. Evaluating the fit of structural equation models: Tests of significance and descriptive goodness-of-fit measures. Methods of psychol res. online, 2003;8:23-74.

Thornton B, Gibbons FX, Gerrard M. Risk perception and prototype perception: Independent process predicting risk behavior. Personal Social Psychol Bull 2002;28:986-99.

Thøgersen J. A model of recycling behaviour, with evidence from Danish source separation programs. International J Res Mark 1994;11:145-63.

Tonglet M, Phillips PS, Read AD. Using the Theory of Planned Behaviour to investigate the determinants of recycling behaviour: a case study from Brixworth, UK. Resour Conserv Recycl 2004a:41;191-214.

Tonglet M, Phillips PS, Bates MP. Determining the drivers for householder pro-environmental behaviour: waste minimisation compared to recycling. Resour Conserv Recycl 2004b:42:27-48.

Verplanken B, Aarts H, van Knippenberg Ad, Moonen A. Habit versus planned behaviour: A field experiment. The Br J Social Psychol 1998;37:111-28.

Webb LT, Sheeran P. Does changing behavioral intentions engender behavior change? A meta-analysis of the experimental evidence. Psychol Bull 2006;132:249-68. 
Table 1. Observed behavior of accepted and declined plastic bags in the pre- and post-intervention assessments

Weekday (Wednesday)

\begin{tabular}{lcccccc}
\hline & \multicolumn{3}{c}{ pre-intervention } & \multicolumn{3}{c}{ post-intervention } \\
\cline { 2 - 7 } & received & declined & $\%$ of decline & received & declined & $\%$ of decline \\
\hline 10:00 12:00 & 342 & 124 & $26.6 \%$ & 396 & 203 & $33.9 \%$ \\
\hline 13:00 15:00 & 342 & 121 & $26.1 \%$ & 349 & 134 & $27.7 \%$ \\
\hline 16:00 18:00 & 565 & 157 & $21.7 \%$ & 452 & 171 & $27.4 \%$ \\
\hline Total & 1249 & 402 & $24.3 \%$ & 1197 & 508 & $29.8 \%$ \\
\hline Saturday & \multicolumn{7}{c}{5} \\
\hline & received & declined & $\%$ of decline & received & declined & $\%$ of decline \\
\hline & 616 & 175 & $22.1 \%$ & 534 & 195 & $26.7 \%$ \\
\hline 10:00 12:00 & 624 & 129 & $17.1 \%$ & 565 & 188 & $25.0 \%$ \\
\hline 13:00 15:00 & 734 & 176 & $19.3 \%$ & 653 & 217 & $24.9 \%$ \\
\hline 16:00 18:00 & 1974 & 480 & $19.6 \%$ & 1752 & 600 & $25.5 \%$ \\
\hline total & \multicolumn{7}{c}{ pre-intervention } \\
\hline
\end{tabular}


Table 2. The demographics of all respondents who submitted valid questionnaires in the pre- and post-intervention

\begin{tabular}{lccc}
\hline & pre-intervention & post-intervention & \\
\hline Gender & & & \\
Male & $27 \%$ & $26 \%$ & $\chi^{2}(1)=.13$ \\
Female & $73 \%$ & $74 \%$ & \\
Age & & & \\
under 19 & $0.2 \%$ & $0.5 \%$ & \\
$20-29$ & $3 \%$ & $4 \%$ & \\
$30-39$ & $17 \%$ & $16 \%$ & $\chi^{2}(6)=8.02$ \\
$40-49$ & $22 \%$ & $19 \%$ & \\
$50-59$ & $28 \%$ & $24 \%$ & \\
$60-69$ & $21 \%$ & $25 \%$ & \\
over 70 & $9 \%$ & $12 \%$ & \\
Occupation & & & \\
homemaker & $32 \%$ & $34 \%$ & \\
full-time or part time worker & $55 \%$ & $49 \%$ & \\
student & $0.2 \%$ & $1 \%$ & \\
miscellaneous (e.g. retired) & $13 \%$ & $16 \%$ & \\
Possession of reusable shopping bag & & & \\
None & $20 \%$ & $16 \%$ & \\
1 & $27 \%$ & $23 \%$ & \\
$2-3$ & $42 \%$ & $46 \%$ & $\chi^{2}(3)=6.07$ \\
more than 4 & $11 \%$ & $15 \%$ & \\
\hline
\end{tabular}


Table 3. Means and standard deviations of the indicators for the pre- and post-intervention samples intervention

\begin{tabular}{|c|c|c|c|c|c|c|c|c|}
\hline & & Attitude & Subjective Norm & Descriptive Norm & $\begin{array}{c}\text { Perceived } \\
\text { Behavioral } \\
\text { Control }\end{array}$ & $\begin{array}{l}\text { Behavioral } \\
\text { Intention }\end{array}$ & $\begin{array}{l}\text { Behavioral } \\
\text { Willingness }\end{array}$ & $\begin{array}{c}\text { Anti-Plastic Bag } \\
\text { Behavior }\end{array}$ \\
\hline \multirow{5}{*}{ pre } & $\operatorname{total}(n=441)$ & $3.88(.90)$ & $2.26(.82)$ & $3.75(.84)$ & $3.82(.89)$ & $3.42(1.08)$ & $3.22(1.29)$ & $-.14(.83)$ \\
\hline & supermarket $\mathrm{A}(n=112)$ & $3.80(.82)$ & $2.34(.81)$ & $3.75(.77)$ & $3.91(.79)$ & $3.44(1.08)$ & $3.26(1.23)$ & $-.12(.82)$ \\
\hline & supermarket $\mathrm{B}(n=168)$ & $3.88(.92)$ & $2.19(.77)$ & $3.78(.81) \quad \mathrm{a}$ & $3.78(.93)$ & $3.39(1.03)$ & $3.09(1.33)$ & $-.19(.83)$ \\
\hline & supermarket $\mathrm{C}(n=105)$ & $3.97(.92)$ & $2.22(.87)$ & $3.86(.92) \quad b$ & $3.77(.92)$ & $3.26(1.14)$ & $3.43(1.23)$ & $-.19(.86)$ \\
\hline & supermarket $\mathrm{D}(n=56)$ & $3.82(.96)$ & $2.33(.91)$ & $3.40(.82) \quad a b$ & $3.86(.94)$ & $3.71(1.10)$ & $3.06(1.36)$ & $.03(.77)$ \\
\hline \multirow{5}{*}{ post } & $\operatorname{total}(n=429)$ & $3.95(.94)$ & $2.48(.96)$ & $3.57(.84)$ & $4.05(.82)$ & $3.67(1.10)$ & $2.78(1.30)$ & $.07(.86)$ \\
\hline & supermarket $\mathrm{A}(n=104)$ & $3.88(1.04)$ & $2.41(.90)$ & $3.60(.73) \quad \mathrm{a}$ & $4.01(.83)$ & $3.66(1.15) \mathrm{a}$ & $2.63(1.27)$ & $.07(.89) \quad \mathrm{a}$ \\
\hline & supermarket $\mathrm{B}(n=155)$ & $3.97(.87)$ & $2.38(.96) \quad \mathrm{a}$ & $3.60(.80) \quad b$ & $3.92(.79)$ & $3.55(1.06) \mathrm{b}$ & $2.95(1.32) \mathrm{a}$ & $.02(.82) \quad \mathrm{b}$ \\
\hline & supermarket $\mathrm{C}(n=113)$ & $3.85(.99)$ & $2.46(.95)$ & $3.78(.87) \quad \mathrm{c}$ & $4.33(.84) \quad \mathrm{a}$ & $3.48(1.09) \mathrm{c}$ & $2.95(1.29) \mathrm{b}$ & $-.10(.90) \quad \mathrm{c}$ \\
\hline & supermarket $\mathrm{D}(n=57)$ & $4.12(.79)$ & $2.82(.98) \quad \mathrm{a}$ & $3.11(.80) \quad a b c$ & $4.05(.72) \quad \mathrm{a}$ & $4.33(.83) \quad a b c$ & $2.38(1.24) \mathrm{ab}$ & $.54(.69) \quad a b c$ \\
\hline \multicolumn{2}{|c|}{ intervention : $F(1,862)$} & 1.79 & $14.91 * *$ & 8.46 ** & $16.90 * *$ & $15.37 * *$ & $27.00 * *$ & 16.69 ** \\
\hline \multicolumn{2}{|c|}{ intervention(supermarket): $F(6,862)$} & .97 & $2.25 *$ & $6.33 * *$ & 1.92 & $5.67 * *$ & $2.85 * *$ & $4.42 * *$ \\
\hline
\end{tabular}

Note. $* p<.05, * * p<.01$, SDs are inside parentheses. The common superscript indicates the significant difference between the constructs (5\% Bonferroni adjustment). Anti-plastic bag behavior is a standardized variable. 
Table 4. Correlations among indicators between the pre- and post-intervention samples

\begin{tabular}{lccccccc}
\hline & $1 . \mathrm{Att}$ & $2 . \mathrm{SN}$ & $3 . \mathrm{DN}$ & $4 . \mathrm{PBC}$ & $5 . \mathrm{BI}$ & \multicolumn{1}{l}{$6 . \mathrm{BW}$} & \multicolumn{1}{l}{. B } \\
\hline $1 . \mathrm{Att}$ & - & $.41 * *$ & -.01 & $.47 * *$ & $.57 * *$ & $-.23 * *$ & $.29 * *$ \\
$2 . \mathrm{SN}$ & $.50 * *$ & - & -.07 & $.25 * *$ & $.58 * *$ & $-.17 * *$ & $.22 * *$ \\
$3 . \mathrm{DN}$ & .01 & -.07 & - & $-.11 *$ & $-.15 * *$ & $.18 * *$ & $-.18 * *$ \\
$4 . \mathrm{PBC}$ & $.55 * *$ & $.39 * *$ & $-.10 *$ & - & $.60 * *$ & $-.41 * *$ & $.39 * *$ \\
$5 . \mathrm{BI}$ & $.66 * *$ & $.55 * *$ & -.08 & $.74 * *$ & - & $-.48 * *$ & $.56 * *$ \\
$6 . \mathrm{BW}$ & $-.28 * *$ & $-.25 * *$ & $.13 * *$ & $-.41 * *$ & $-.46 * *$ & - & $-.54 * *$ \\
$7 . \mathrm{B}$ & $.49 * *$ & $.35 * *$ & $-.16 * *$ & $.61 * *$ & $.67 * *$ & $-.47 * *$ & - \\
\hline
\end{tabular}

Note. ${ }^{*} p<.05,{ }^{* *} p<.01$. Correlations in the pre-intervention sample are above the diagonal and correlations in the post-intervention sample are below diagonal. Att $=$ attitude; $\mathrm{SN}=$ subjective norm; $\mathrm{DN}=$ descriptive norm; $\mathrm{PBC}=$ perceived behavioral control; $\mathrm{BI}=$ behavioral intention; $\mathrm{BW}=$ behavioral willingness; $\mathrm{B}=$ anti-plastic bag 
Table 5. Model fit indexes of constrained and unconstrained models comparing pre-intervention to post-intervention samples.

\begin{tabular}{|c|c|c|c|c|c|c|c|c|c|c|}
\hline Model & $\chi^{2}$ & $d f$ & $p$ & $\Delta \chi^{2}$ & $\Delta d f$ & $\Delta p$ & AIC & GFI & CFI & RMSEA \\
\hline Unconstrained model & 82.49 & 12 & $<.01$ & - & - & - & 170.49 & .98 & .97 & .08 \\
\hline Full constrained model & 121.38 & 21 & $<.01$ & 38.89 & 9 & $<.01$ & 191.38 & .96 & .95 & .07 \\
\hline Model without $\mathrm{BI}$ to $\mathrm{B}$ path constraint & 107.79 & 20 & $<.01$ & 13.60 & 1 & $<.01$ & 179.79 & .97 & .96 & .07 \\
\hline $\begin{array}{l}\text { Model without BI to B \& BW to B path } \\
\text { constraints }\end{array}$ & 101.56 & 19 & $<.01$ & 6.23 & 1 & $<.05$ & 175.56 & .97 & .96 & .07 \\
\hline $\begin{array}{l}\text { Model without } \mathrm{BI} \text { to } \mathrm{B}, \mathrm{BW} \text { to } \mathrm{B} \& \mathrm{PBC} \text { to } \\
\mathrm{BI} \text { path constraints }\end{array}$ & 93.95 & 18 & $<.01$ & 7.61 & 1 & $<.05$ & 169.95 & .97 & .96 & .07 \\
\hline $\begin{array}{l}\text { Model without } \mathrm{BI} \text { to } \mathrm{B}, \mathrm{BW} \text { to } \mathrm{B}, \mathrm{PBC} \text { to } \mathrm{BI} \\
\& \mathrm{PBC} \text { to } \mathrm{B} \text { path constraints }\end{array}$ & 88.86 & 17 & $<.01$ & 5.08 & 1 & $<.05$ & 166.86 & .97 & .97 & .07 \\
\hline
\end{tabular}

Note. $\mathrm{PBC}=$ perceived behavioral control; $\mathrm{BI}=$ behavioral intention; $\mathrm{BW}=$ behavioral willingness, $\mathrm{B}=$ anti-plastic bag behavior. 


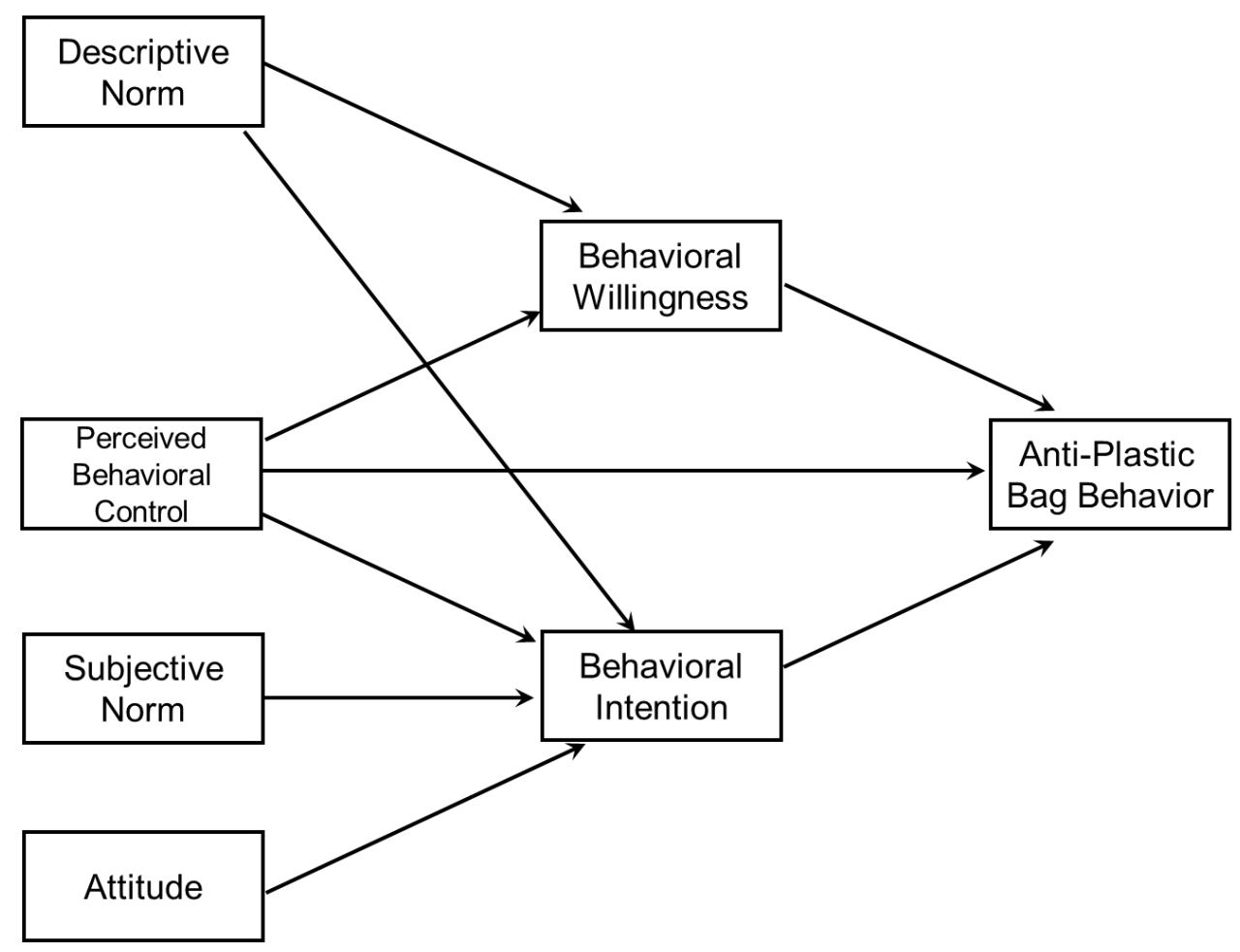

Figure 1. Theoretical model for anti-plastic bag behavior 
Pre-intervention phase

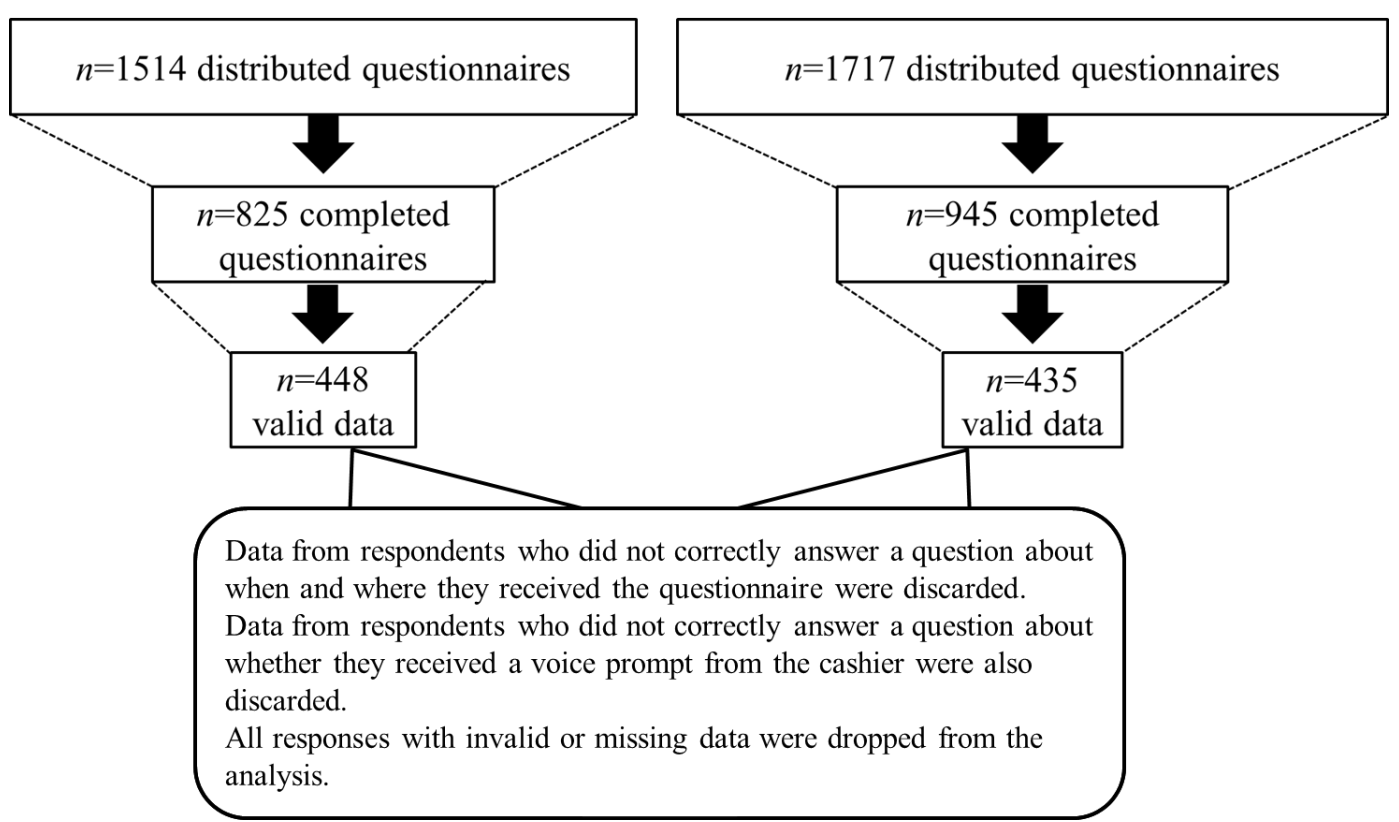

Post-intervention phase

Figure 2. Collection of questionnaires 


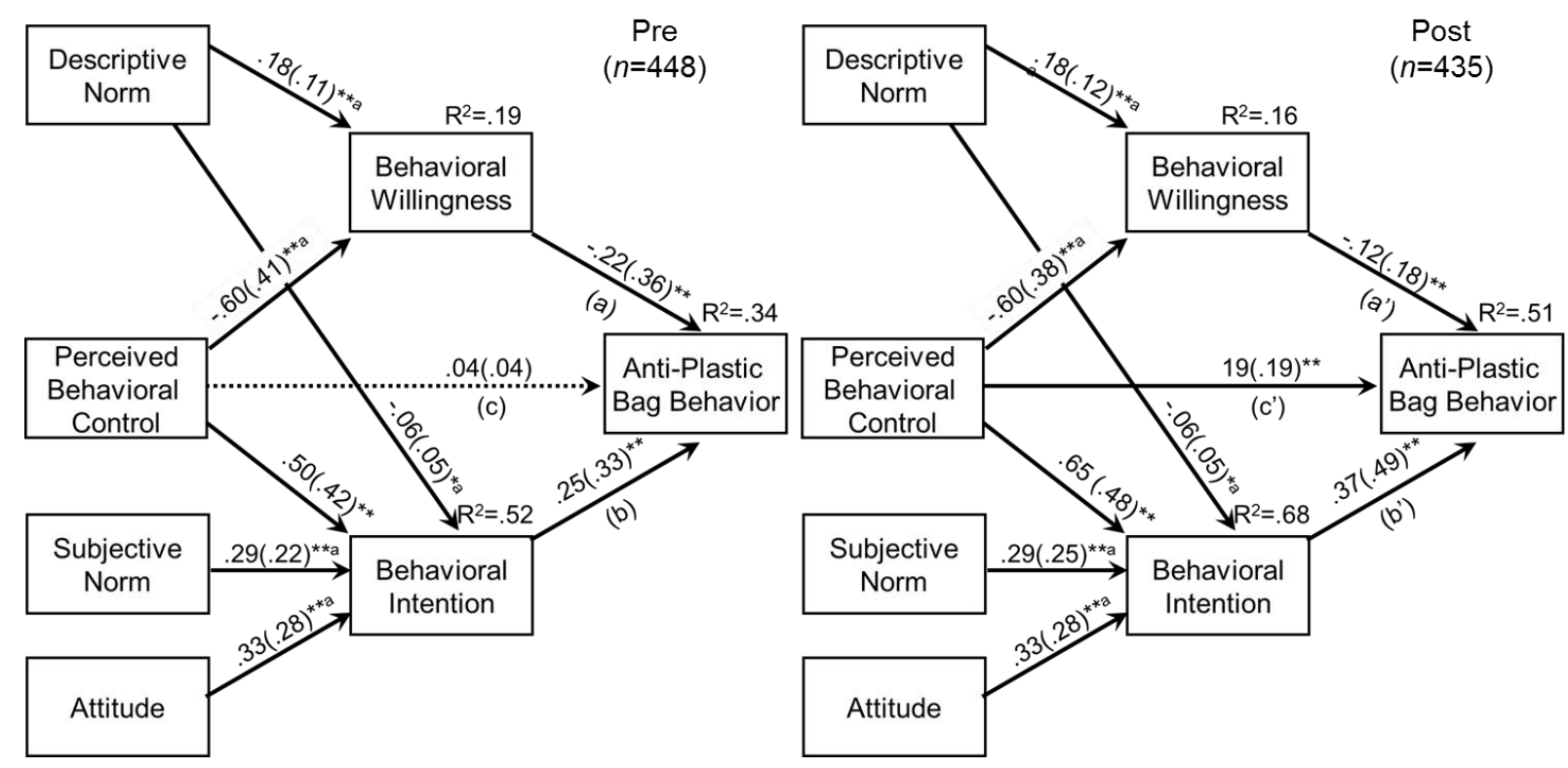

Figure 3. Multi-group analysis between the pre- and post-intervention samples

Note. The coefficients of the pre-intervention sample $(n=448)$ are at the left side and the coefficients of the post-intervention sample $(n=435)$ are at the right side. Un-standardized coefficients are outside parentheses and standardized coefficients are inside parentheses. The paths with a common superscript mean the constraint of equal path coefficients between the pre- and post- intervention samples. To reduce the complexity of the figure, the correlations and error terms are not shown. $* \mathrm{p}<.05, * * \mathrm{p}<.01$. 
This study implemented a field study to reduce free plastic bags at supermarkets.

The dual motivation model was examined with the intervention, which proposes that pro-environmental behaviors were determined by two motivations.

Voice prompt intervention induced context change and promotes pro-environmental behaviors.

A voice prompt can be introduced at a low cost, compared to other popular economical incentives. 